\title{
Joint genealogical analysis as a tool for diversity evaluation in Pinzgau cattle populations
}

\author{
Ivan Pavlík', Johann Sölkner², Ondrej Kadlečík', Radovan Kasarda', Gábor Mészáros², \\ Christian Fuerst ${ }^{3}$ and Birgit Fuerst-Walt| ${ }^{2}$
}

'Department of Animal Genetics and Breeding Biology, Faculty of Agrobiology and Food Resources, Slovak University of Agriculture in Nitra, Slovakia, ${ }^{2}$ Department of Sustainable Agricultural Systems, Division of Livestock Sciences, University of Natural Resources and Life Sciences, Vienna, Austria, ${ }^{3}$ ZuchtData EDV-Dienstleistungen GmbH, Vienna, Austria

\begin{abstract}
The presented paper gives an overview about genetic diversity in Pinzgau populations in Austria and Slovakia. In total, 12442 animals were included in the study representing the reference population. All living herdbook cows, dual purpose and beef, from both countries with a maximum foreign gene proportion of $12.5 \%$ were considered. Thus, four subpopulations were analysed. Parameters of diversity based on probability of identityby-descent and probability of gene origin were computed by the methods of pedigree analysis. The average inbreeding coefficient (five generations taken into account) was $0.0186(\Delta \mathrm{F}=0.0041), 0.0242(\Delta \mathrm{F}=0.0047), 0.0151(\Delta \mathrm{F}=0.0026)$, and $0.0126(\Delta \mathrm{F}=0.0006)$ in the Austrian dairy $(A D)$, the Austrian beef $(A B)$, the Slovak dairy (SD) and the Slovak beef $(S B)$ subpopulation, respectively. Effective population size ranged from 122.5 (AD) to 809.4 (SB). Effective number of founders was 67.3 and 106.6 in $A D$ and SD and 73 and 212.3 in the $A B$ and SB subpopulations. Effective number of ancestors was $29.59 ; 34.42 ; 42.36$ and 73.81 in $A D, A B$, $S D$ and $S B$, respectively. Effective number of founder genomes was $15.32 ; 18.15 ; 23.41$ and 41 in $A D, A B, S D$ and $S B$ subpopulations, respectively. Similarities between subpopulations were calculated based on a cosine approach. The highest similarity was found between $A D$ and $A B$ (cosine value 0.9954$)$. SD and $A D$ subpopulations were very similar (cosine value 0.9181 ).
\end{abstract}

Keywords: diversity, founder, gene origin, inbreeding, Pinzgau cattle

Archiv Tierzucht 57 (2014) 14, 1-12

doi: 10.7482/0003-9438-57-014

Corresponding author:

Ivan Pavlík, email: ivan.pavliktn@gmail.com

Slovak University of Agriculture in Nitra, Tr. A. Hlinku 2, 94976 Nitra, Slovakia
Received: 22 January 2014 Accepted: 29 April 2014 Online: 23 May 2014

(c) 2014 by the authors; licensee Leibniz Institute for Farm Animal Biology (FBN), Dummerstorf, Germany. This is an Open Access article distributed under the terms and conditions of the Creative Commons Attribution 3.0 License (http://creativecommons.org/licenses/by/3.0/). 
Abbreviations: AB: Austrian beef, AD: Austrian dairy, $\triangle \mathrm{F}$ : increase in inbreeding, $\mathrm{F}$ : inbreeding coefficient, $\mathrm{F}_{\text {all }}$ : inbreeding coefficient for all generations, $\mathrm{F}_{5}$ : inbreeding coefficient for 5 generations, $F_{10}$ : inbreeding coefficient for 10 generations, $f$ : number of founder, $f_{a}$ : effective number of ancestors, $\mathrm{f}_{\mathrm{e}}$ : effective number of founders, SB: Slovak beef, SD: Slovak dairy, $\mathrm{N}_{\mathrm{e}}$ : effective population size, $\mathrm{N}_{\mathrm{g}}$ : effective number of founder genomes

\section{Introduction}

An important way to assess the diversity of populations is to use measures calculated from genealogical information. Pedigree-derived parameters provide expectations across the whole genome, allowing the estimation (and maintenance) of variability at unknown sites. One of the most important measures that genealogical analysis allows is the probability of identity-by-descent (Mäki-Tanila et al. 2010).

Genetic diversity within populations is necessary for adaptive capacity and avoidance of inbreeding depression on the long term (Oliehoek \& Bijma 2009). The negative effects of inbreeding depression on production and functional traits were e.g. presented by FuerstWaltl \& Fuerst (2012) in Austrian Braunvieh, Maximini et al. (2011) in Austrian Simmental bulls, González-Recio et al. (2007) in Spanish Holstein, Kasarda \& Kadlečík (2007) in Slovak Pinzgau and McParland et al. (2007) in Irish dairy and beef breeds.

The application of pedigree analysis in livestock diversity assessments was presented by Maignel et al. (1996) and Boichard et al. (1997) in French dairy cattle populations. Pedigree analysis in Pinzgau cattle was published by Baumung \& Sölkner (2002) in Austria and Kadlečík et al. (2011) in Slovakia.

The parameters obtained from genealogical analysis provide useful tools for predicting the consequences for a given management scheme or for designing the resources for a conservation programme, where general variability is to be maintained (Mäki-Tanila et al. 2010).

The aim of this paper was to perform the genealogical analysis of Pinzgau cattle in Austria and Slovakia as well as to determine the similarities between populations.

\section{Material and methods}

\section{Pinzgau breed}

Pinzgau is an original Alpine cattle breed from the region Pinzgau in Salzburg, Austria. Animals of this breed had been imported to Slovak mountain areas in the 19th century. In the central European region, it is nowadays considered as a dual-purpose breed with good milk and beef performance. Due to the changing economic conditions, a significant decline of Pinzgau cows' number can be seen in all countries with dairy herds. This situation is particularly striking in Slovakia where the majority of Pinzgau cows has been involved in crossbreeding; especially with Red Holstein-Friesian cattle. In 2012, the average milk yield was $5524 \mathrm{~kg}$ (3.87\% fat, 3.28\% protein) in Austria (ZAR 2013) and $4453 \mathrm{~kg}$ (3.85\% fat, 3.39\% protein) in Slovakia (Breeding Services of Slovak Republic 2012). Pinzgau is a unique cattle breed suitable for mountain regions with good longevity, fertility and adaptability under poor production conditions. According to FAO's Global Plan of Action (FAO 2007), it is therefore 
necessary to preserve the breed and its genetic diversity. The providing of EU subsidies for endangered local breeds (Duclos \& Hiemstra 2010) is a very important precondition to avoid further reduction of the breed.

\section{Data}

Pedigree information was provided by ZuchtData EDV-Dienstleistungen GmbH, Austria and The Breeding Services of Slovak Republic. The data set consisted of living pure-bred Pinzgau herdbook cows (max. 12.5\% foreign gene proportion) and was represented by 12442 animals all together. These animals set up the reference population. Cows were divided into four different subpopulations: 1 . Austrian dairy ( $A D, n=7479)$, 2. Austrian beef $(A B, n=3143)$, 3. Slovak dairy $(S D, n=1183)$, 4. Slovak beef $(S B, n=637)$. Dairy subpopulations were represented by dual-purpose and beef subpopulations by suckler cows, respectively. Slovak pedigree data was extended with Austrian pedigree information. The modification of databases and basic statistical procedures were performed by using of program packages SAS 9.2 (SAS Institute, Inc., Cary, NC, USA).

\section{Methods}

The presented analysis can be divided into the four following steps:

1. assessment of pedigree quality,

2. computation of diversity parameters,

3. searching of the most important ancestors according to their individual marginal contributions,

4. computation of similarities between populations (subpopulations).

The first procedure evaluates the quality of pedigree information. One of the best measures to characterize pedigree quality is the complete generation equivalent. It is defined as the sum of the proportion of known ancestors over all traced generations (Maignel et al. 1996). Further, we used the following groups of measures for determination of genetic diversity in the given reference population:

a) parameters based on probability of identity-by-descent - inbreeding coefficient $(F)$, increase in inbreeding $(\Delta \mathrm{F})$, effective population size computed via $\Delta \mathrm{F}\left(\mathrm{N}_{\mathrm{e}}\right)$.

b) parameters based on probability of gene origin - number of founders (f), effective number of founders $\left(f_{e}\right)$, effective number of ancestors $\left(f_{a}\right)$ and effective number of founder genomes $\left(\mathrm{N}_{\mathrm{g}}\right)$.

All calculations of measures describing genetic variability were carried out using the Fortran software package PEDIG (Boichard 2002, 2007).

\section{Inbreeding coefficient (F)}

Wright (1965) defines the coefficient $F$ as the correlation between homologous genes of uniting gametes under a given mating pattern, relative to the total array of these in random derivatives of the foundation stock. The same author defines $F$ as the probability that an individual has two identical alleles by descent. This coefficient was computed following the algorithm of Meuwissen \& Luo (1992). In our case, F was calculated using five generations $\left(F_{5}\right)$, ten generations $\left(\mathrm{F}_{10}\right)$ and all generations traced $\left(\mathrm{F}_{\text {all }}\right)$ as well. 
Increase in inbreeding $(\Delta F)$

This very important measure can be defined as the difference between the average inbreeding coefficients of the offspring generation, compared with the average inbreeding coefficient of the parents' generation (Kearney et al. 2004). It is calculated for each generation by means of the classical formula

$$
\Delta F=\frac{F_{t}-F_{t-1}}{1-F_{t-1}}
$$

where $F_{t}$ and $F_{t-1}$ are the average inbreeding at the $t$-th generation (Gutiérrez et al. 2009). A modification of this measure is the individual increase in inbreeding $\left(\Delta F_{i}\right)$ computed for each individual as

$$
\Delta F_{i}=1-\sqrt[t-1]{1-F_{i}}
$$

where $F_{i}$ is the individual coefficient of inbreeding and $t$ is the equivalent complete generation (Maignel et al. 1996, Gutiérrez et al. 2009). Most authors state that the trend of increase in inbreeding is more important than the inbreeding coefficient.

Effective population size computed via increase in inbreeding $(N)$

The effective population size is the size of an ideal population showing the same rate of increase in inbreeding per generation as the non-ideal population (Sölkner et al. 1998). Effective population size was computed according to the classical formula

$$
N_{e}=\frac{1}{2 \Delta \mathrm{F}}
$$

where $\Delta F$ is increase in inbreeding.

\section{Number of founders $(f)$}

Lacy (1989) defined founder as an animal with no known genetic relationship to any other animal in the pedigree except for its own descendants.

\section{Effective number of founders $(f)$}

This measure is defined as the number of founders that would produce a population with the same diversity of founder alleles as in the reference population if all founders had contributed equally to each descendant generation. It was computed as

$$
f_{e}=1 / \Sigma_{k=1}^{f} q_{k}^{2}
$$

where $q_{k}$ is the probability of gene origin of the $k$ ancestor (Lacy 1989). 


\section{Effective number of ancestors $\left(f_{d}\right)$}

Defined as the number of equally contributing ancestors that will produce the same genetic diversity as assessed in the population. It was computed as

$$
f_{a}=1 / \sum_{j=1}^{a} q_{j}^{2}
$$

where $q_{j}$ is the marginal contribution of ancestor $j$ (Boichard et al. 1997).

\section{Effective number of founder genomes $\left(N_{q}\right)$}

This measure describes the probability that a gene from the founder population (i.e. founder allele) has been maintained in the reference population for a given locus and how balanced their frequencies are. It was computed as

$$
N_{g}=1 / 2 \sum_{k=1}^{2 f} c_{k}^{2}
$$

where $c_{k}$ is the frequency of founder allele $k$ (Boichard et al. 1997). Each founder is represented by two unique founder alleles, therefore $2 f$ founder alleles are presented in the population. A simulation is run spreading the founder alleles throughout the whole pedigree by randomly sampling one allele from each parent to create the genotype of a progeny (Sölkner et al. 1998). This procedure was replicated several times. In our case, 10000 replications were used for all populations.

\section{Ancestor contributions}

We computed individual marginal contributions of the most important ancestors in each subpopulation. The marginal contribution of an individual quantifies its contribution to the reference population, which has not previously been explained by greater contributing individuals (Boichard et al. 1997).

\section{Similarity between subpopulations}

The goal of this procedure was to find out the level of similarity between subpopulations, because the gene migration between populations in Austria and Slovakia as well as between dairy and beef population can be observed. The proportions of genes for all founders in the total populations were calculated for each subpopulation. As each founder is represented by two alleles in the approach leading to $N_{g^{\prime}}$ the sum of these two alleles was used to represent the proportion contributed by the founder. To compare two subpopulations $A$ and $B$, the differences in contributions to these subpopulations of each founder present in the total population were used (Sölkner et al. 1998). We used cosine of angle $\theta$ between the vectors of square roots of founder frequencies in subpopulations A and B according Jacquard's (1974) formula:

$$
\cos \theta=\sum_{i=1}^{f} \sqrt{q_{A i} q_{B i}}
$$


This parameter has the advantage of being bounced by 0 and 1, a value of 1 indicating perfect agreement in founder contributions (Sölkner et al. 1998).

\section{Results and discussion}

\section{Quality of pedigrees}

The total population consisted of 12442 individuals. Austrian cows represented $85.37 \%$ and Slovak ones $14.63 \%$. Only pure-bred cows were used in our investigation. The total Slovak Pinzgau population is represented by 3101 herdbook cows in 2012, of those 1820 pure-bred ones (Breeding Services of Slovak Republic 2012).

The quality of pedigree information is a very important precondition to get reliable results of diversity assessments. The complete generation equivalent was used as the best measure to describe pedigree depth. Our results point out better quality of Austrian pedigrees in both subpopulations (average complete generation equivalents 7.36 in dairy cows and 7.10 in suckler cows). In the SD and SB subpopulations, the average complete generation equivalents were 5.14 and 4.03, respectively. The main reason of deeper Austrian pedigrees can be a longer history of animal recording in Austria than in Slovakia as well as possible incomplete pedigree availability for imported animals. The overview of complete generation equivalents in given supbopulations is presented in Table 1. For a reference population of Austrian pure-bred Pinzgau cattle born between 1993 to 1997, Baumung \& Sölkner (2002) presented a lower complete generation equivalent (5.33) than that of Tux-Zillertal (2.52) and Carinthian Blond (1.73; reference populations all living animals for both breeds). The same measure computed by Kadlečík et al. (2011) in Slovak Pinzgau population including crossbred animals was 3.16. Kadlečík et al. (2007) presented that the high completeness of pedigrees was well-preserved in parental generation of Slovak Pinzgau cattle.

Table 1

Complete generation equivalents for the four subpopulations under study

\begin{tabular}{lccccc}
\hline Subpopulation & \multicolumn{5}{c}{ Complete generation equivalent } \\
& $\mathrm{n}$ & mean & s.d. & $\min$ & $\max$ \\
\hline Austrian dairy & 7479 & 7.36 & 1.13 & 1.00 & 9.52 \\
Austrian beef & 3143 & 7.10 & 1.22 & 1.00 & 9.40 \\
Slovak dairy & 1183 & 5.14 & 0.89 & 2.30 & 7.62 \\
Slovak beef & 637 & 4.03 & 1.00 & 1.63 & 7.02 \\
\hline
\end{tabular}

$\mathrm{n}$ : number of animals in the reference population, mean: arithmetic mean, sd: standard deviation, min: minimum, max: maximum

Measures based on probability of identity-by-descent

The average values of the measures based on probability of identity-by-descent are presented in Table 2.

Inbreeding is a very important factor affecting genetic diversity. It is responsible for an increase of homozygosity. Uncontrolled inbreeding leads to inbreeding depression which negative consequences have been presented by many authors. Especially small endangered populations are very sensitive to inbreeding level. To make our results comparable between 
subpopulations, we used an approach where an inbreeding coefficient was computed from five generations traced $\left(F_{5}\right)$, ten generations traced $\left(F_{10}\right)$ and all generations traced $\left(F_{\text {all }}\right)$. The best measure is $F_{5}$ because most of animals had rather complete pedigrees up to the 5 th generation. The $F_{5}$ was $0.0186 ; 0.0242 ; 0.0151$ and 0.0126 in AD, AB, SD and SB subpopulation, respectively. As expected, inbreeding showed an increasing tendency with increasing number of generations included into computation. The greatest value of $F_{5}$ for a single animal was found in SD population (0.318). According to the $F 5$ value there were $82.16 \%$ inbred animals in $A D, 77.35 \%$ in $A B, 61.96 \%$ in SD and $16.17 \%$ in SB subpopulation (Figure 1). Inbred animals were those which had $\mathrm{F}>0$. High proportions of inbred animals point out that in future a more pronounced increase of inbreeding can be expected. Kadlečík et al. (2011) presented a lower inbreeding coefficient $(F=0.0057)$ for the SD Pinzgau population but crossbred animals were included into this investigation and unknown pedigree information of Red HolsteinFriesian ancestors could lead to lower and thus underestimated $F$ values. Baumung \& Sölkner (2002) computed an average $F=0.0209$ with $\Delta F=0.0066$ in Austrian Original Pinzgau. The inbreeding coefficient was roughly $3 \%$ in endangered Tux-Zillertal population. Bouquet et al. (2011) presented the average inbreeding coefficients of roughly 1\% in European Charolais and Limousine cattle.

Table 2

Diversity measures based on probability of identity-by-descent

\begin{tabular}{lcccc}
\hline & Austrian dairy & Austrian beef & Slovak dairy & Slovak beef \\
\hline $\mathrm{F}_{5}$ & 0.0186 & 0.0242 & 0.0151 & 0.0126 \\
$\mathrm{~F}_{10}$ & 0.0322 & 0.0345 & 0.0160 & 0.0130 \\
$\mathrm{~F}_{\text {all }}$ & 0.0322 & 0.0345 & 0.0160 & 0.0130 \\
$\Delta \mathrm{F}$ & 0.0041 & 0.0047 & 0.0026 & 0.0006 \\
$\mathrm{~N}_{\mathrm{e}}$ & 122.45 & 107.03 & 188.94 & 809.40 \\
\hline
\end{tabular}

$\mathrm{F}_{5}=$ inbreeding coefficient for 5 generations, $\mathrm{F}_{10}$ =inbreeding coefficient for 10 generations, $\mathrm{F}_{\text {all }}=$ inbreeding coefficient for all generations, $\Delta \mathrm{F}$ =increase in inbreeding, $\mathrm{N}_{\mathrm{e}}$ =effective population size

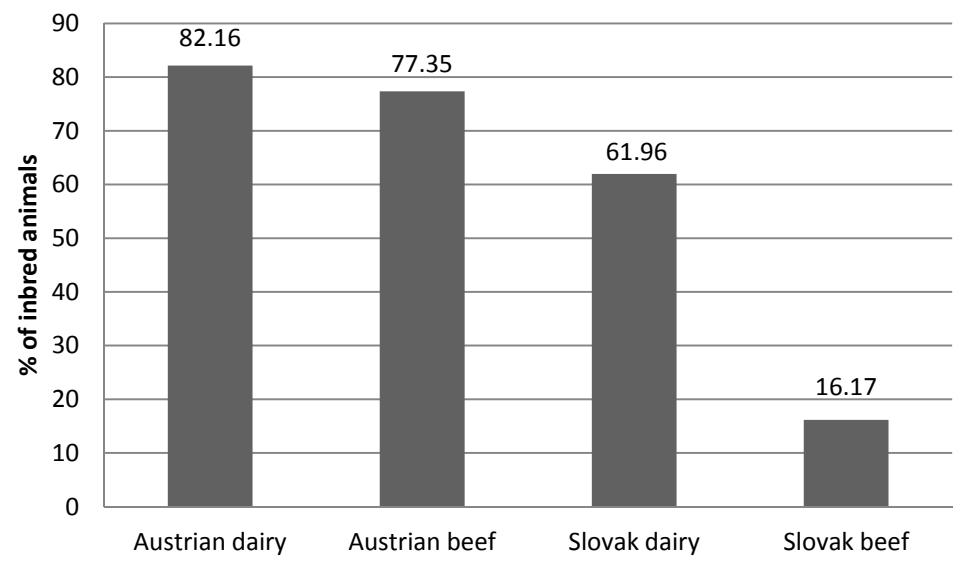

Figure 1

Proportion of inbred animals in given Pinzgau subpopulations (5 generations taken into account) 
According to FAO (1998) increase in inbreeding of $\Delta F>0.01$ can cause serious problems to maintain fitness in a breed. Greater increase in inbreeding reduces the diversity significantly. None of our subpopulations included in this study exceeded this value. It was 0.0041; $0.0047 ; 0.0026$ and 0.0006 in $A D, A B, S D$ and $S B$, respectively. Maignel et al. (1996) stated an increase in inbreeding of over 0.01 in French Holstein (0.0109), Normande (0.0107) and Tarentaise (0.0183). The effective population size is very useful measure to characterize the level of endangerment of the breed. In our study, the effective population size computed via increase in inbreeding was used. FAO (1998) regards the value $N_{e}<100$ as the critical limit to consider a breed as endangered. All our subpopulations were outside this limit. The effective population size in SD (188.9) was greater than in AD (122.55). An increase of $\Delta F$ may lead to decline of effective population size. Maignel et al. (1996) computed $N_{e}=46$ and $N_{e}=47$ in French Holstein and Normande, respectively, which was incomparably lower that in our subpopulations. Effective population size is presumably overestimated in Slovakia, especially in the beef population due to lower pedigree depth. Higher pedigree completeness would lead to lower effective population size in that subpopulation.

\section{Measures based on probability of gene origin}

The basic measures of diversity based on probability of gene origin are presented in Table 3 .

Table 3

Diversity measures based on probability of gene origin

\begin{tabular}{lcccc}
\hline & Austrian dairy & Austrian beef & Slovak dairy & Slovak beef \\
\hline Animals & 7479 & 3141 & 1180 & 636 \\
$\mathrm{f}$ & 6301 & 4279 & 2529 & 1542 \\
$\mathrm{f}_{\mathrm{e}}$ & 67.3 & 73.0 & 106.6 & 212.3 \\
$\mathrm{f}_{\mathrm{a}}$ & 29.59 & 34.42 & 42.36 & 73.81 \\
$\mathrm{~N}_{\mathrm{g}}$ & 15.32 & 18.15 & 23.41 & 41.00 \\
\hline
\end{tabular}

$\mathrm{f}=$ number of founder, $\mathrm{f}_{\mathrm{e}}=$ effective number of founders, $\mathrm{f}_{\mathrm{a}}=$ effective number of ancestors, $\mathrm{N}_{g}$ =effective number of founder genomes

The highest number of founders was found in the biggest population (AD). The effective number of founders was incomparably lower than number of founders in all subpopulations. This fact points out unbalanced use of founders in process of populations' evolution. The difference between $f_{e}$ and $f_{a}$ in all investigated populations points out the bottleneck effect occurrence. The highest effective number of ancestors $\left(f_{a}=73.81\right)$ was found in SB population, while the lowest $\left(f_{a}=29.59\right)$ was found in AD population. The highest proportion of founder genes was maintained in SB population $\left(N_{g}=41\right)$, where the effective number of founders reached the highest value $\left(f_{e}=212.3\right)$ as well. Greater values observed in both Slovak subpopulations can however be the result of less complete pedigree information. Recently, Siderits et al. (2013) showed that a relatively small improvement of the pedigree information may lead to apparent changes in the measurements of genetic variability. McParland et al. (2007) computed the effective number of founders from 55 in Irish Simmental to 357 in Irish Charolais and effective number of founder genomes from 24 in Irish Hereford to 58 in Irish Limousin. These results confirmed bottleneck as important factor affecting the diversity. Kadlečík et al. (2011) reported a value of $f_{e}=141$ and $f_{a}=51$ in Slovak Pinzgau, Baumung \& 
Sölkner (2002) found $f_{e}=108.5$ and $N_{g}=29.2$ in Original Pinzgau. Sölkner et al. (1998) computed $f_{e}=66.2, f_{a}=46.7$ and $N_{g}=32.0$ in Austrian Pinzgau. Unbalanced use of founders according to measures based on probability of gene origin was confirmed by Maignel et al. (1996) in French dairy cattle breeds. The difference between $f_{e}$ and $N_{g}$ confirmed genetic drift affecting genetic diversity loss in our population under study.

\section{Genetic contributions}

In each livestock population we can find some superior animals which have intensive impact on given population. Nowadays, thanks to globalization and strong international collaboration such animals and their progeny can be found in many different countries. Exchange of genetic material is an important way to preserve endangered breeds including Pinzgau. The most important ancestors were determined according to their individual contributions in subpopulations under study. Some animals were common for all subpopulations. Sire ADRIAN was the most important ancestor in each subpopulation. This bull is great-grandfather of sire MASCHA which was on the second to fourth place in all subpopulations' ranking of ancestors. The highest Adrian's contribution can be observed in the Austrian dairy population (0.1180) while in the Slovak beef population it was only 0.0608 . The Austrian list of top ten ancestors consisted only of animals born in Austria except the Red Holstein-Friesian sire BRAND RED born in Canada. Two dams were listed among the top ten contributing ancestors in both Austrian subpopulations while in Slovak subpopulations there were no dams among the top ten ancestors. The Slovak dairy population has been very intensively influenced by Austrian animals. The proof of this fact is the proportion of Austrian sires in the list of the most important ancestors in Slovak subpopulations. Except one, all sires in top ten ancestors were born in Austria. Top ancestors in Austrian subpopulations belong to the older generation (1964-1989) while in Slovak subpopulations we can find younger ancestors (1967-2004) with the highest marginal contribution.

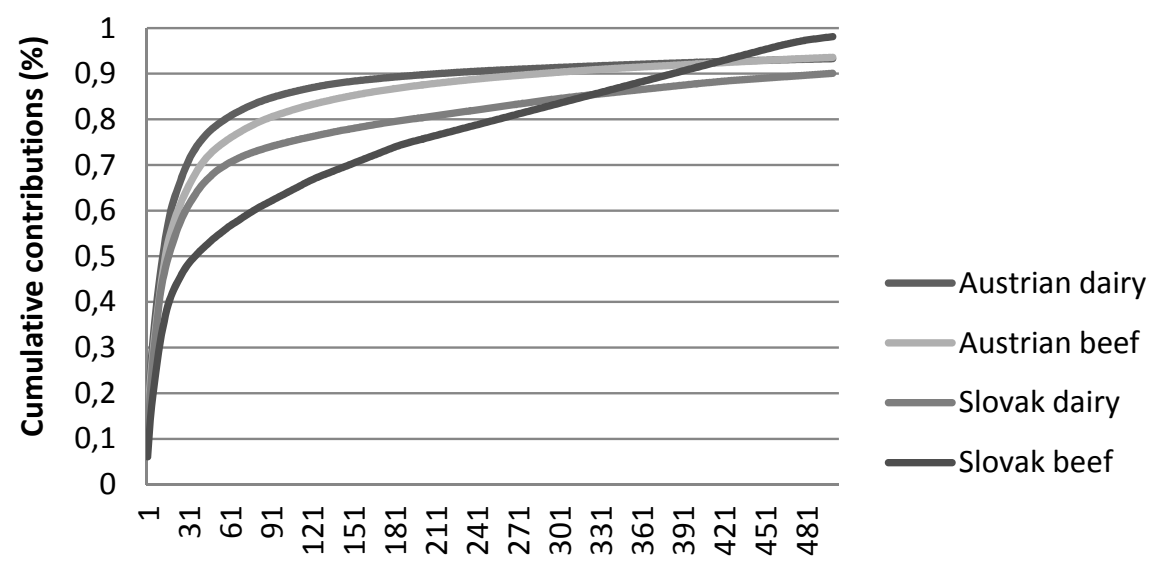

\section{Number of ancestors}

Figure 2

Cumulative contributions of ancestors in evaluated subpopulations 
The cumulative contributions of 500 most important ancestors in investigated subpopulations are presented in Figure 2. The curves of cumulative contributions in $A D, A B$ and $S D$ are very similar while the curve of SB subpopulation differs from previous subpopulations. The SB subpopulation was the smallest and originated from the dairy subpopulation only few years ago. The cumulative contributions of 500 ancestors were $0.9328 ; 0.9357 ; 0.9006$ and 0.9812 in $A D, A B, S D$ and SB subpopulations, respectively. Very similar trends in cumulative contributions of Irish dairy and beef cattle breeds were published by McParland et al. (2007).

\section{Similarities between subpopulations}

Slovak breeding work is dependent on the import of Al sires from Austria for blood refreshment. To understand the process of populations' creation we have tried to evaluate the similarities between the Austrian and Slovak subpopulations. One of the measures is the cosine value of angle $\theta$ between the vectors of square roots of founder frequencies in two populations. When this value is close to 1 there is higher similarity between populations. $A$ high similarity between populations means that the populations have inherited very similar genetic contributions from the same founders. In our case the highest similarity was found between $A D$ and $A B$ subpopulations (0.9954). The lowest similarity can be observed between AB and SB subpopulation (0.8601). The SB population has no long tradition (recent 10 years) and originated from former dairy herds, which was proofed by cosine value 0.9242. In Austria, beef Pinzgau has an incomparably longer history. During the next years an increase in beef populations can be expected in Austria as well as in Slovakia. The similarity between AD and SD subpopulations is high (0.9181) confirming very close relationship between both subpopulations. The same methodology was used by Sölkner et al. (1998) in Austrian cattle breeds and Bouquet et al. (2011) in European Charolais and Limousin populations.

Table 4

Similarities between subpopulations

\begin{tabular}{ccc}
\hline Population $A$ & Population B & cosine value \\
\hline AD & AB & 0.9954 \\
AD & SD & 0.9181 \\
AD & SB & 0.8652 \\
AB & SD & 0.9128 \\
AB & SB & 0.8601 \\
SD & SB & 0.9242 \\
\hline
\end{tabular}

$\mathrm{AD}=$ Austrian dairy, $\mathrm{AB}=$ Austrian beef, $\mathrm{SD}=$ Slovak dairy, $\mathrm{SB}=$ Slovak beef

Pinzgau is considered as endangered breed in Austria as well as in Slovakia because the total population of the dual-purpose type has significantly decreased in recent years. From the genetical point of view, we cannot state that it is endangered population. In breeding programmes, the use of information based on genetic diversity studies can be a very important tool to maintain the population. Pedigree analysis is a very useful method which can ensure reliable output information for making decisions with regard to breeding strategies. Currently, the average inbreeding level in the analysed subpopulations is not alarming. However, future mating strategies should even more strongly aim at the reduction 
of inbreeding. It is necessary to optimize mating plans to avoid inbreeding problems and maintain fitness.

Intensive international cooperation is necessary to exchange the breeding material. Austrian and Slovak populations are very similar which was confirmed by our results. The Slovak population can be a suitable genetic reserve for Austria in case of epidemic or other unexpected situations. Therefore, common diversity evaluations and breeding strategies should be very useful and help the breed and farmers in both countries.

\section{Acknowledgements}

The authors thankZuchtData EDV-Dienstleistungen GmbH and Plemenárske služby Slovenskej republiky (Breeding Services of Slovak Republic) for providing of pedigree information. The authors would like to acknowledge the Scientific and Technological Cooperation project of OeAD (SK14/2011) and APVV SK-AT-00012-10 »Genetic diversity of cattle and horse breeds« which made the publication of this paper possible.

\section{References}

Baumung R, Sölkner J (2002) Analysis of pedigrees of Tux-Zillertal, Carinthian Blond and Original Pinzgau cattle population in Austria. J Anim Breed Genet 119, 175-181

Boichard D (2002) Pedig: a fortran package for pedigree analysis suited to large populations. In: Proc 7th WCGALP, Montpellier, France, 28-13

Boichard D (2007) PEDIG: A Fortran Package for Pedigree Analysis Suited for Large Populations. https://qgsp. jouy.inra.fr/index.php?option=com_content\&view $=$ article\&id=53\&ltemid $=57$ [last accessed 15.05.2014]

Boichard D, Maignel L, Verrier E (1997) The value of using probabilities of gene origin to measure genetic variability in population. Genet Sel Evol 29, 5-23

Bouquet A, Venot E, Laloe D, Forabosco F, Fogh A, Pabiou T, Moore K, Eriksson JA, Renand G, Phocas F (2011) Genetic structure of the European Charolais and limousin cattle metapopulations using pedigree analyses. J Anim Sci 89, 1719-1730

Breeding Services of Slovak republic (2012) [Results of dairy herd milk recording in Slovak republic for control year 2011-2012]. Brochure of Breeding Services of Slovak republic, Bratislava, Slovakia [in Slovak]

Duclos D, Hiemstra SJ (2010) State of local cattle breeds in Europe. In: SJ Hiemstra, Y Haas, A Mäki-Tanila, Gandini G (eds.) Local cattle breeds in Europe. Development of policies and strategies for self-sustaining breeds. Wageningen, The Netherlands, 40-56

FAO (1998) Secondary Guidelines for Development of National Farm Animal Genetic Resources Management Plans. Food and agriculture organization of the United Nations. Rome, Italy http://www.fao.org/ag/ againfo/programmes/en/lead/toolbox/indust/sml-popn.pdf [last accessed 15.05.2014]

FAO (2007) Global Plan of Action for Animal Genetic Resources and the Interlaken Declaration. Commission on genetic resources for food and agriculture. Food and agriculture organization of the United Nations. Rome, Italy ftp://ftp.fao.org/docrep/fao/010/a1404e/a1404e00.pdf [last accessed 15.05.2014]

Fuerst-Waltl B, Fuerst C (2012) Effect of inbreeding depression on survival of Austrian Brown Swiss calves and heifers. J Dairy Sci 95, 6086-6092

González-Recio O, López de Maturana E, Gutiérrez JP (2007) Inbreeding Depression on Female Fertility and Calving Ease in Spanish Dairy Cattle. J Dairy Sci 90, 5744-5752

Gutiérrez JP, Goyache F, Cervantes I (2009) Endog v 4.6. A computer program for monitoring genetic variability of populations using pedigree information: Users guide. Madrid, Spain

Jacquard A (1974) The genetic structure of populations. Berlin, Germany et al. 
Kearney JF, Wall E, Villanueva B, Coffey MP (2004) Inbreeding Trends and Application of Optimized Selection in the UK Holstein Population. J Dairy Sci 87, 3503-3509

Kadlečík O, Kasarda R, Mészáros G, Žitný J, Vavrišínová K (2007) [Pedigree analysis of purebred Pinzgau population]. Acta fytotech zootech 10, 29-32 [in Slovak]

Kadlečík O, Kasarda R, Pavlík I, Hazuchová E (2011) Pedigree Analysis of Slovak Pinzgau Breed. Agric Conspec Sci 76, 165-168

Kasarda R, Kadlečík O (2007) An economic impact of inbreeding in the purebred population of Pinzgau cattle in Slovakia on milk production traits. Czech J Anim Sci 52, 7-11

Lacy RC (1989) Analysis of founder representation in pedigrees: Founder equivalents and founder genome equivalents. Zoo Biol 8, 111-123

Maignel L, Boichard D, Verrier E (1996) Genetic variability of French dairy breeds estimated from pedigree information. Interbull Bull 14, 49-54

Maximini L, Fuerst-Waltl B, Gredler B, Baumung R (2011) Inbreeding Depression on Semen Quality in Austrian Dual-Purpose Simmental Bulls. Reprod Domest Anim 46, e102-e104

Mäki-Tanila A, Fernandez J, Toro M, Meuwissen T (2010) Assessment and management of genetic variation. In: Hiemstra SJ,de Haas Y,Mäki-Tanila A, Gandini G (eds.) Local cattle breeds in Europe. Development of policies and strategies for self-sustaining breeds. Wageningen, The Netherlands, 70-80

McParland S, Kearney JF, Rath M, Berry DP (2007) Inbreeding trends and pedigree analysis of Irish dairy and beef cattle populations. J Anim Sci 85, 322-331

Meuwissen THE, Luo Z (1992) Computing inbreeding coefficients in large populations. Genet Sel Evol 24, 305-313

Oliehoek PA, Bijma P (2009) Effects of pedigree errors on the efficiency of conservation decisions. Genet Sel Evol 41: 9

Siderits M, Baumung R, Fuerst-Waltl B (2013) Pedigree analysis in the German Paint Horse: Genetic variability and the influence of pedigree quality. Livest Sci 151, 152-157

Sölkner J, Filipcic L, Hampshire N (1998) Genetic variability of populations and similarity of subpopulations in Austrian cattle breeds determined by analysis of pedigrees. Anim Sci 67, 249-256

Wright S (1965) The interpretation of population structure by F-statistics with special regard to systems of mating. Evol 19, 395-420

ZAR (2012) [Cattle breeding in Austria 2012]. Brochure of Zentrale Arbeitsgemeinschaft österreichischer Rinderzüchter, Vienna, Austria [in German] 